\title{
Greater Happiness for a Greater Number
}

\section{Is that Possible and Desirable?}

\section{Ruut Veenhoven}

Published online: 30 May 2010

(C) The Author(s) 2010. This article is published with open access at Springerlink.com

\begin{abstract}
Utilitarian philosophy holds that public policy should aim at greater happiness for a greater number of people. This moral tenet meets many objections, on pragmatic grounds it is denounced as unfeasible and on ideological grounds as undesirable. As a result the principle is marginal in policy making. In this paper I consider these classic philosophical qualms in the light of recent empirical research on life-satisfaction. The data show first of all that the principle is feasible; happiness of a great number is possible in contemporary conditions and it is also possible to create more of it. The data also show that the promotion of happiness fits well with other ideals; happiness requires conditions that we value, such as freedom, and happiness fosters matters that we value, such as good health and civil behaviour. Though happiness can conflict with these values in theory, it appears to match them in practice.
\end{abstract}

Keywords Happiness - Life satisfaction - Subjective wellbeing · Utilitarianism · Research synthesis $\cdot$ Hedonism $\cdot$ Cross-cultural

\section{The Greatest Happiness Principle}

During the Middle Ages it was widely believed that happiness is not possible in earthly life and that the basis of morality is in the word of God. These views were contested in the 'Enlightenment'; happiness came to be seen as attainable and morality was regarded as man-made. A lively discussion on the relation between happiness and morality emerged (Mauzi 1960; Buijs 2007) and in that climate an instrumental view on morality appeared, in which ethical codes are seen as ways of securing a happy life.

A similar text was published in Dutch in Ethiek en Maatschappij (Ethics and Society) 2009, 12: 25-50. An earlier English version appeared in: Alex Linley \& Stephen Joseph (Eds.) 'Positive Psychology in Practice' Wiley 2004, chapter 39, pp. 658-678.

R. Veenhoven ( $\square)$

Erasmus University Rotterdam, Rotterdam, The Netherlands

e-mail: veenhoven@fsw.eur.nl 
Much of that enlighted thought is reflected in Jeremy Bentham's (1789) 'Introduction to morals and legislation'. Bentham argues that the moral quality of action should be judged by its consequences on human happiness and in that line he claims that we should aim at the 'greatest happiness for the greatest number'. Bentham defined happiness in terms of psychological experience, as 'the sum of pleasures and pains'. His philosophy is known as 'utilitarianism', because of its emphasis on the utility of behavioral consequences. 'Happyism' would have been a better name, since this utility is seen as contribution to happiness.

When applied at the level of individual choice (actor utilitarianism), this tenet runs into some difficulties. One problem is that often one cannot foresee what the balance of effects on happiness will be. Another problem is that the principle deems well-intended behavior to be a-moral if it happens to pan out adversely. Imagine the case of a loving mother who saves the life of her sick child, a child that grows up to be a criminal; mothers can seldom foresee a child's future and can hardly be reproached for their unconditional motherly love.

The principle is better suited for judging general rules, such as the rule that mothers should care for their sick children. It is fairly evident that adherence to this rule will add to the happiness of a great number. Following such rules is then morally correct, even if consequences might be negative in a particular case. This variant is known as 'Rule-Utilitarianism'.

When applied to public policy the principle is also called 'Political Utilitarianism' and holds that institutions, laws and social policy should maximize happiness. Bentham used the greatest happiness principle in that way and discussed the implications of that principle for property laws and the death penalty. Interest in such applications is rising these days. For example, Layard (2005) pleas on this ground for higher income tax and more investment in mental health care.

\subsection{Objections Against the Principle}

The greatest happiness principle is well known, and it is a standard subject in every introduction to moral philosophy. Yet the principle is seldom put into practice. Why is this? The answer to this question is also to be found in most introductory philosophy books: Utilitarianism is typically rejected, both on pragmatic and on moral grounds.

\section{Pragmatic Objections}

Application of the greatest happiness principle requires that we know what happiness is and that we can predict the consequences of behavioral alternatives on it. It also requires that we can check the results of applying this principle, that is, that we can measure resulting gains in happiness. At a more basic level the principle assumes that happiness can be affected by what we do.

All of this is typically denied. It is claimed that happiness is an elusive concept, and one that we cannot measure. As a consequence we can only make guesses about the effects on happiness on policy alternatives and can never verify our suppositions. Some even see happiness as an immutable trait that cannot be influenced. Such criticism often ends with the conclusion that we would do better to stick to more palpable seasoned virtues, such as 'justice' and 'equality'.

\section{Moral Objections}

The main ethical objection holds that the 'greatest happiness principle' justifies a-moral means, such as genetic manipulation, mind-control and dictatorship. Another common objection is that happiness is mere pleasure or an illusionary matter and hence not very valuable in and of itself. It is also claimed that happiness spoils; in particular that it fosters 
irresponsible consumerism and that it makes us less sensitive to the suffering of others. Much of these ethical qualms feature in Huxley's (1935) 'Brave New World'.

\subsection{Plan of this Paper}

All this is armchair theorizing, mainly by philosophers and novelists. How do these objections stand up to empirical tests? Below I will first consider the pragmatic objections (Sect. 2) and next the ideological qualms (Sect. 3). I will draw on the empirical findings on happiness gathered in the World Database of Happiness (Veenhoven 2010a). ${ }^{1}$

\section{Is Happiness a Practicable Goal?}

Pragmatic objections against the greatest happiness principle are many. The most basic objection is that happiness cannot be defined and that all talk about happiness is therefore mere rhetoric. The second objection is that happiness cannot be measured, so that we can never establish an absolute degree and number for happiness. A third objection holds that lasting happiness of a great number is not possible, that we can at best find some relief in fleeting moments of delusion. The last claim is that we cannot bring about happiness. These objections will strike many readers of this journal as outdated. Still it is useful to consider the evidence for and against for each of them.

\subsection{Can Happiness be Defined?}

The word happiness has different meanings and these meanings are often mixed up, which gives the concept a reputation for being elusive. Yet a 'confusion of tongues' about a word does not mean that no substantive meaning can be defined. Let us consider what meanings are involved and which of these is most appropriate as a final policy aim.

\subsubsection{Four Qualities of Life}

When used in a broad sense, the word happiness is synonymous with 'quality of life' or 'well-being'. In this meaning it denotes that life is good, but does not specify what is good about life. The word is also used in more specific ways, and these can be clarified with the help of the classification of qualities of life presented in Table 1.

Vertically there is a difference between chances for a good life and actual outcomes of life. This distinction is quite common in the field of public-health research. Pre-conditions for good health, such as adequate nutrition and professional care are seldom confused up with health itself. Yet means and ends are less well distinguished in the discussion on happiness.

Horizontally there is a distinction between 'external' and 'internal' qualities. In the first case the quality is in the environment, in the latter it is in the individual. This distinction is also commonly made in public health. External pathogens are distinguished from inner afflictions. Yet again this basic insight is lacking in many discussions about happiness.

Together, these two dichotomies mark four qualities of life, all of which have been denoted by the word 'happiness'.

1 Referces to specific sections in the World Database of Happiness are made in footnotes, which involve links to the particular webpages. 
Table 1 Four qualities of life

\begin{tabular}{lll}
\hline & Outer qualities & Inner qualities \\
\hline $\begin{array}{ll}\text { Life-chances } \\
\text { Life-results }\end{array}$ & $\begin{array}{l}\text { Livability of environment } \\
\text { Utility of life }\end{array}$ & $\begin{array}{l}\text { Life-ability of the person } \\
\text { Satisfaction }\end{array}$ \\
\hline
\end{tabular}

\section{Livability of the Environment}

The left top quadrant denotes the meaning of good living conditions. Often the terms 'quality-of-life' and 'wellbeing' are used in this particular meaning, especially in the writings of ecologists and sociologists. Economists sometimes use the term 'welfare' for this meaning. 'Livability' is a better word, because it refers explicitly to a characteristic of the environment and does not carry the connotation of Paradise. Politicians and social reformers typically stress this quality of life.

\section{Life-Ability of the Person}

The right top quadrant denotes inner life-chances. That is: how well we are equipped to cope with the problems of life. This aspect of the good life is also known by different names. In biology the phenomenon is referred to as 'adaptive potential'. On other occasions it is denoted by the medical term 'health', in the medium variant of the word. ${ }^{2}$ Sen (1992) calls this quality of life variant 'capability'. I prefer the simple term 'life-ability', which contrasts elegantly with 'livability'. This quality of life is central in the thinking of therapists and educators.

\section{Utility of Life}

The left bottom quadrant represents the notion that a good life must be good for something more than itself. This presumes some higher value, such as ecological preservation or cultural development. In fact, there is a myriad of values on which the utility of life can be judged. There is no current generic for these external turnouts of life. Gerson (1976: 795) referred to these kinds as 'transcendental' conceptions of quality of life. Another appellation is 'meaning of life', which then denotes 'true' significance instead of mere subjective sense of meaning. I prefer the more simple 'utility of life', admitting that this label may also give rise to misunderstanding. ${ }^{3}$ Moral advisors, such as your pastor, emphasize this quality of life.

\section{Satisfaction with Life}

Finally, the bottom right quadrant represents the inner outcomes of life. That is the quality in the eye of the beholder. As we deal with conscious humans this quality boils down to subjective appreciation of life. This is commonly referred to by terms such as 'subjective wellbeing', 'life-satisfaction' and 'happiness' in a limited sense of the word. ${ }^{4}$ There is no professional interest group that stresses this meaning, and this seems to be one of the reasons for the reservations surrounding the greatest happiness principle.

Which of these four meanings of the word happiness is most appropriate as an end-goal for social policy? I think the last one. Commonly policy aims at improving life-chances by, for example, providing better housing or education, that is, in the upper half of Table 1. Yet more is not always better and some opportunities may be more critical than others. The

\footnotetext{
${ }^{2}$ There are three main meanings or health: The maxi variant is all the good (WHO definition), the medium variant is life-ability, and the mini-variant is absence of physical defect.

3 A problem with this name is that the utilitarians used the word utility for subjective appreciation of life, the sum of pleasures and pains.

4 This quality-of-life is the subject of the Journal of Happiness Studies.
} 
Table 2 Four kinds of satisfaction

\begin{tabular}{lll}
\hline & Passing & Enduring \\
\hline Part of life & Pleasure & Part-satisfaction \\
Life-as-a-whole & Peak-experience & Life-satisfaction \\
\hline
\end{tabular}

very problem is that we need a criterion to assign priorities among the many life-chances policymakers want to improve. That criterion should be found in the outcomes of life, so in the lower half of Table 1 . There, 'utility' provides no workable criterion, since external effects are many and can be valued differently. 'Satisfaction with life' is a better criterion, since it reflects the degree to which external living-conditions 'fit' with inner life-abilities. Satisfaction is also the subjective experience Jeremy Bentham had in mind. ${ }^{5}$

\subsubsection{Four Kinds of Satisfaction}

This brings us to the question of what 'satisfaction' is precisely. This is also a word with multiple meanings and again we can elucidate these meaning using a simple scheme. Table 2 is based on two distinctions; vertically between satisfaction with 'parts' of life versus satisfaction with life 'as-a-whole', and horizontally between 'passing' satisfaction and 'enduring' satisfaction. These two bi-partitions yield again a four-fold taxonomy.

\section{Pleasures}

Passing satisfaction with a part of life is called 'pleasure'. Pleasures can be sensoric, such as a glass of good wine, or mental, such as the reading of this text. The idea that we should maximize such satisfactions is called 'hedonism'.

\section{Part-Satisfactions}

Enduring satisfaction with a part of life is referred to as 'part-satisfaction'. Such satisfactions can concern a domain of life, such as working-life, and an aspect of life, such as its variety. Sometimes the word happiness is used for such part-satisfactions, in particular for satisfaction with one's career.

\section{Peak-Experience}

Passing satisfaction can be about life-as-a-whole, in particular when the experience is intense and 'oceanic'. This kind of satisfaction is usually referred to as 'peak-experience'. When poets write about happiness they usually describe an experience of this kind. Likewise religious writings use the word happiness often in the sense of a mystical ecstasis. Another word for this type of satisfaction is 'Enlightenment'. 6

\section{Life-Satisfaction}

Enduring satisfaction with one's life-as-a-whole is called 'life-satisfaction' and also commonly referred to as 'happiness'. Elsewhere I have delineated this concept in more detail and defined happiness as 'the overall appreciation of one's life-as-a-whole' (Veenhoven 1984, 2000a).

\footnotetext{
5 Jeremy Bentham used the word 'happiness' for the sum of pleasures and pains, and as such his concepts belongs in the satisfaction quadrant of Table 1 . This is not to say that his view on happiness is identical with life satisfaction in Table 2. There are different interpretations of what kind of satisfaction Bentham aimed at precisely. Since Bentham extended his principle to animals, he seems to have aimed at what I call ' hedonic level of affect'.

${ }^{6}$ Religious extasis is not the kind of 'Enlightenment' referred to in the introduction of this paper.
} 
In my view, life-satisfaction is most appropriate as a policy goal. Enduring satisfaction is clearly more valuable than passing satisfactions and satisfaction with life-as-a-whole is also of more worth than mere part-satisfaction. Moreover, life-satisfaction is probably of greater significance, since it signals the degree to which human needs are being met. I will come back to this point in Sect. 3.2.1.

\subsubsection{Components of Happiness}

There are different views on what 'satisfaction' with life is precisely. Some authors see that as an affective state and equate happiness with good feelings (e.g. Wessman and Ricks (1966: 240/1). Others see satisfaction rather as a cognitive judgment, e.g. McDowel and Newell (1987: 204) describe life-satisfaction as a "Personal assessment of one's condition compared to an external reference standard or to one's aspirations". Several authors assume that both affect and cognition are involved. Diener defines 'Subjective Well-Being' (SWB) as being satisfied with life (cognition), while feeling good (affect) (Diener et al. 1997: 25). Likewise Sumner (1996: 145/6) describes 'being happy' as: "having a certain kind of positive attitude toward your life, which in the fullest form has both a cognitive and an affective component".

I follow that latter view, assuming that humans are capable of evaluating their life in two ways. We have in common with all higher animals that we can appraise our situation affectively. We feel good or bad about particular things and our mood level signals overall adaptation. As in animals these affective appraisals are automatic, but unlike other animals, humans can reflect on this experience. We have an idea of how we have felt over the last year, while a cat does not. Humans can also judge life cognitively by comparing life-as-itis with notions of how-it-should-be.

Most human evaluations are based on both sources of information, that is: intuitive affective appraisal and cognitively guided evaluation. The mix depends mainly on the object. Tangible things such as our income are typically evaluated by comparison; intangible matters such as sexual attractiveness are evaluated by how it feels. In the case of our life-as-a-whole, these appraisals do not necessarily coincide. We may feel fine generally, but nevertheless be aware that we failed to realize our aspirations. Or we may have surpassed our aspirations, but nevertheless feel miserable.

I refer to these components as hedonic level of affect and contentment and see them as sub-totals in the inclusive evaluation of life, which I call overall happiness. This distinction is discussed in more detail in Veenhoven (1984 ch2). It fits a common distinction in philosophy between three views on happiness: the 'hedonistic view', the 'desire fulfillment' view and the 'hybrid' view (Parfit 1984). This view is further developed in my paper 'How do we assess how happy we are?'(Veenhoven 2009).

\section{Hedonic Level of Affect}

Hedonic level of affect is the degree to which various affects that someone experiences are pleasant in character and this reflects typically in 'mood'. A person's average hedonic level of affect can be assessed over different periods of time: a week, a year, as well as over a lifetime. The focus here is on 'characteristic' hedonic level. The concept does not presume subjective awareness of that average level.

\section{Contentment}

Contentment is the degree to which an individual perceives his/her aspirations are met. The concept presupposes that the individual has developed some conscious wants and has formed an idea about their realization. The factual correctness of this idea is not at stake. The concept concerns the individual's subjective perception. 


\section{Preponderance of Affect}

There is mounting evidence that affective experience dominates the overall evaluation of life. This fits the theory that affects are the basic orientation system in mammals and that cognition evolved later in evolution and functions as an addition rather than as a substitute. This view and the evidence for it is discussed in more detail in Veenhoven (2009). The related theory that hedonic level reflects gratification of universal human 'needs' is developed in Veenhoven (1991, 2005, 2009, 2010b).

In sum: Happiness can be defined as the 'overall enjoyment of one's life as-a-whole'. This encompassing judgment is based on both affective and cognitive appraisals of life.

\subsection{Can Happiness be Measured?}

A common objection against the 'greatest happiness principle' is that happiness cannot be measured. This objection applies to most of the above-discussed meanings of the word, but does it apply to happiness in the sense of life-satisfaction?

By definition, this kind of happiness is something we have on our mind and consequently we can measure it using questions. That is, simply asking people how much they enjoy their life-as-a-whole. Questions on happiness can be posed in various contexts; clinical interviews, life-review questionnaires and survey interviews. The questions can also be posed in different ways; directly or indirectly, and by means of single or multiple questions.

\section{Self-Reports}

There are many reservations about self-report measures of happiness: people might not be able to oversee their life, ego-defense might distort the judgment and social desirability could give rise to rosy answers. Because of this, early investigators experimented with indirect questioning. Happiness was measured by a clinical interview, by content analysis of diaries and using projective methods such as the Thematic Apperception Test. These methods are quite laborious and their validity is not beyond doubt. Hence, direct questions have also been used from the beginning. A careful comparison of these methods showed that direct questioning yields the same information at a lower cost (Wessman and Ricks 1966).

\section{Common Survey Questions}

Because happiness can be measured with single direct questions, it has become a common item in large-scale surveys among the general population in many countries. A common question reads:

Taking all together, how satisfied or dissatisfied are you currently with your life as a whole?

1

$2 \quad 3 \quad 4 \quad 5$

$6 \quad 7$

8

9

10

Dissatisfied

Satisfied

Many more questions and answer formats have been used. All acceptable questions are documented in full detail in the collection 'Measures of Happiness', ${ }^{7}$ which is part of the 'World Database of Happiness' (Veenhoven 2010a).

\footnotetext{
7 Avaialble at http://worlddatabaseofhappiness.eur.nl/hap_quer/hqi_fp.htm. The collection provides not only full text of the measures (mostly survey questions), but also links to research findings based on these measures.
} 


\section{Validity}

Though these questions are fairly clear, responses can be flawed in several ways. Responses may reflect how happy people think they should be, rather than how happy they actually feel and it is also possible that people present themselves happier as than they actually are. These suspicions have given rise to numerous validation studies. Elsewhere I have reviewed this research and concluded that there is no evidence that responses to these questions measure something other than what they are meant to measure (Veenhoven 1984: chapter 3, Veenhoven 1998). Though this is no guarantee that research will never reveal a deficiency, we can trust these measures of happiness for the time being.

\section{Reliability}

Research has also shown that responses are affected by minor variations in wording and ordering of questions and by situational factors, such as the race of the interviewer or the weather. As a result the same person may score six in one investigation and seven in another. This lack of precision hampers analyses at the individual level. It is less of a problem when average happiness in groups is compared, since random fluctuations tend to balance. This is typically the case when happiness is used in policy evaluation.

\section{Comparability}

Still, the objection is made that responses on such questions are not comparable, because a score of six does not mean the same for everybody. A common philosophical argument for this position is that happiness depends on the realization of wants and that these wants differ across persons and cultures (Smart and Williams 1973). Yet it is not at all sure that happiness depends on the realization of idiosyncratic wants. The available data are more in line with the theory that it depends on the gratification of universal needs (Veenhoven 1991, 2009, 2010b). I will come back on this point in the later discussion on the 'signal function' of happiness in Sect 3.2.1.

A related qualm holds that happiness is a typical western concept that is not recognized in other cultures. Yet happiness is recognized in facial expression all over the world (Ekman and Friesen 1975) and words for it exist in all languages. Likewise, there is hardly any difference in 'don't know' responses to survey questions about happiness, the percentage being below 2\% in almost all countries of the world (Veenhoven 2010b).

Another objection is that happiness is a unique experience that cannot be communicated on an equivalent scale. ${ }^{8}$ This qualm roots also in a constructivist view of man. Yet from an evolutionary point of view it is unlikely that we differ very much. As in the case of pain, there will be a common human spectrum of experience. In the related functional 'signal' view of affect it is not plausible either that happiness is something idiosyncratic.

The data also tell a different story. If happiness cannot be communicated on an equivalent scale, there will be little correlation between subjective happiness and objective living conditions. Yet research shows several sizable correlations, some of which are presented in the Tables 4, 5 and 6 of this article. Particularly revealing is the $75 \%$ explained variance at the bottom of Table 4 , which denotes a close to perfect correlation

\footnotetext{
8 This objection is also phrased in terms of required 'level of measurement'. In that context it is argued that happiness is measured at the ordinal level, while cardinal level of measurement is required or at least interval level. Substantively that means that we cannot compare happiness if a rating of eight means something different for one person than for another. Methodlogically it means that we cannot perform mathematical operations that require at least interval level of measurement, such as computing means. The substantive objection is discussed shortly in this text and is examined in more detail in Veenhoven 2001 and 2010a. The methodological objection has been considered by VanPraag and Ferrer-i-Carbonell (2004) who found no difference with the results of methods that avoid ordinal ordering, such as probit analysis.
} 
between objective quality of society and average life satisfaction of its members. ${ }^{9}$ Likewise, incomparability of self reported happiness should manifest in a low correlation with objective indicators of how well we thrive. In that context, the relation with longevity is illustrative: follow-up of individuals shows that happiness is a strong predictor of how long we live (Veenhoven 2008b) and comparison across nations shows a +.70 correlation between average happiness and statistical life expectancy. ${ }^{10}$

Lastly there is methodological reservation about possible cultural bias in the measurement of happiness, due to problems with translation of keywords and cultural variation in response tendencies. Elsewhere I have looked for empirical evidence for these distortions, but did not find any (Veenhoven 1993: chapter 5). In this context the $75 \%$ explained variance in Table 4 is also telling. Measurement error can at worst be responsible for $25 \%$ of the observed difference in average happiness across nations The error margin is probably much lower, since we cannot quantify all societal qualities exhaustively and because there is also inevitable measurement error in the measurement of objective characteristics of nations. Probably the error in the measurement of happiness in nations is no more than $5-10 \%$.

The comparability of happiness is discussed in more detail in: Diener and Oishi (2004) VanPraag and Ferrer-i-Carbonell (2004) and Veenhoven (2001, 2008a).

In sum: Happiness as life-satisfaction is measurable with direct questioning and is well comparable across persons and nations. Hence happiness of a great number can be assessed using surveys.

\subsection{Is Happiness Possible?}

Aiming at happiness for a great number has often been denounced as 'illusionary', because long-term term happiness is a fantasy and certainly not happiness for a great number.

This criticism has many fathers. In some religions the belief is that man has been expelled from Paradise: earthly existence is not to be enjoyed, we are here to chasten our souls. Classic psychologists have advanced more profane reasons. Freud (1929) saw happiness as a short-lived orgasmic experience that comes forth from the release of primitive urges. Hence he believed that happiness is not compatible with the demands of civilized society and that modern man is therefore doomed to chronic unhappiness. In the same vein, Adorno believed that happiness is a mere temporary mental escape from misery, mostly at the cost of reality control (Rath 2002).

The psychological literature on 'adaptation' is less pessimistic, but it too denies the possibility of enduring happiness for a great number. It assumes that aspirations follow achievements, and hence concludes that happiness does not last. It is also inferred that periods of happiness and unhappiness oscillate over a lifetime and that the average level is therefore typically neutral. Likewise, social comparison is also seen to result in a neutral average and enduring happiness is only possible for a 'happy few' (Brickman and Campbell 1971).

If all this is true, utilitarians can still go for the least possible unhappiness, but must miss out on the progress optimism from which the idea emerged.

\footnotetext{
9 Similar analyses using more nation characteristics on a smaller number of nations (due to data limitations) show explained variances up to $85 \%$.

${ }^{10}$ World Database of Happiness, Finding report Happiness and Livability of one's nation: http://www. worlddatabaseofhappiness.eur.nl/hap_cor/top_sub.php?code=N7 (subsection N7.2.1.3).
} 


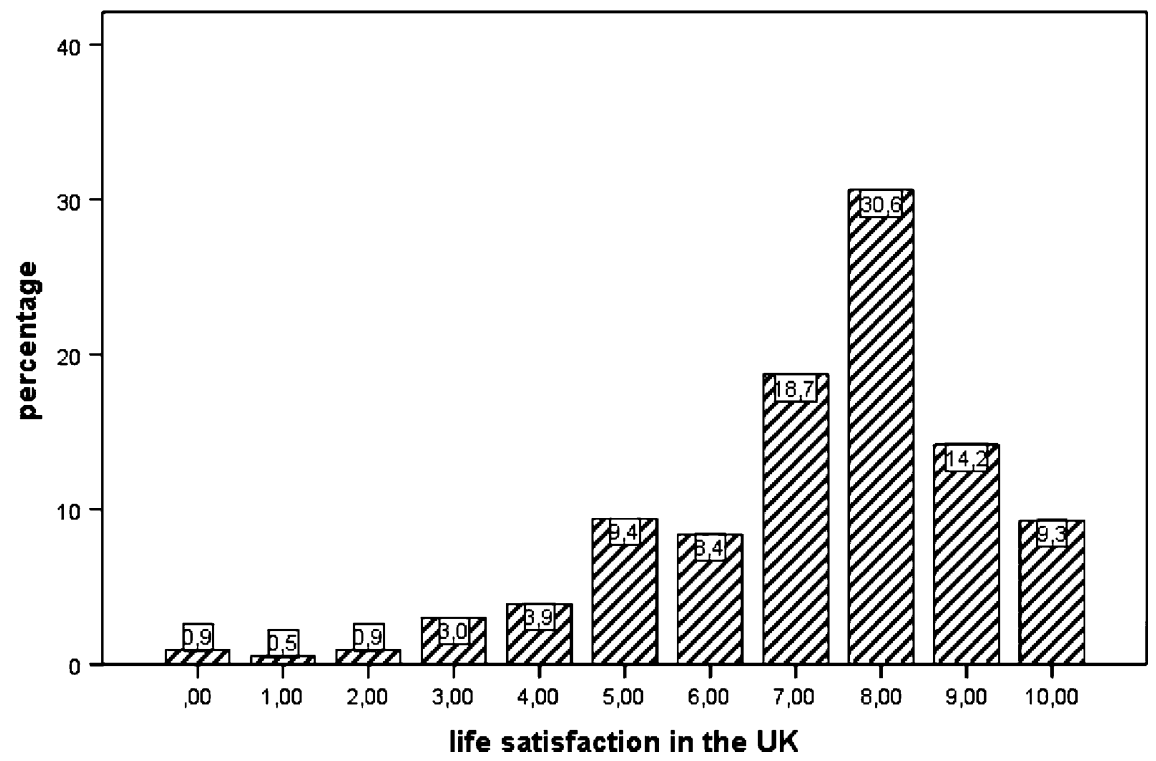

Fig. 1 Life-satisfaction in the UK 2006. Source: European Social Survey 2006

\subsubsection{Enduring Happiness}

Figure 1 presents the distribution of responses to the 10-step question on life-satisfaction in the UK. The most frequent responses are 7, 8 and 9 and less than $10 \%$ scores below neutral. The average is 7,2 . This result implies that most inhabitants of the UK feel happy most of the time. That view has been corroborated by yearly follow-up studies over many years (e.g. Ehrhardt et al. 2000) and by studies that use the technique of experience sampling (e.g. Schimmack and Diener 2003).

\subsubsection{Happiness for a Great Number}

The high level of happiness is not unique to the UK. Table 3 shows similar averages in other western nations. In fact, average happiness tends to be above neutral in most countries of the world. So happiness for a great number is apparently possible. All this is in flat contradiction to Freudian theory, which predicts averages below four everywhere and also defies adaptation theory that predicts universal averages around five.

In sum: Enduring happiness for a great number of people is possible.

\subsection{Can Happiness be Manufactured?}

The observation that most people can be happy does not mean that they can be made happier by public policy. Like the wind, happiness could be a natural phenomenon beyond our control. Several arguments have been raised in support of this view.

A common reasoning holds that happiness is too complex a thing to be controlled. In this line it is argued that conditions for happiness differ across cultures and the dynamics of happiness are of a chaotic nature, and one that will probably never be sufficiently understood. 
Table 3 Life-satisfaction in nations around 2006 Average scores on scale $0-10$

\begin{tabular}{lr}
\hline Denmark & 8,4 \\
Switzerland & 8,1 \\
Mexico & 8,0 \\
Sweden & 7.7 \\
Canada & 7,6 \\
UK & 7.2 \\
USA & 7,0 \\
Indonesia & 6,6 \\
Japan & 6,2 \\
China & 6,0 \\
India & 5,9 \\
Russia & 5,4 \\
Iraq & 4,3 \\
Zimbabwe & 3,2 \\
\hline
\end{tabular}

Source: World Database of

Happiness (Veenhoven 2010), collection Happiness in Nations (World Database of Happiness, Rank report Average Happiness in Nations: http://world databaseofhappiness.eur.nl/ hap_nat/findingreports/Rank Report_AverageHappiness.htm)

The claim that happiness is not makable is also argumented with a reversed reasoning. The reasoning is then that we understand happiness sufficiently well to realize that it cannot be raised. One argument is that happiness depends on comparison and that any improvement is therefore nullified by 'reference drift' (VanPraag 1993). Another claim in this context is that happiness is a trait-like matter and hence not sensitive to any improvement in living conditions at all.

All this boils down to the conclusion that planned promotion of happiness is an illusion.

\subsubsection{Can We Know Conditions for Happiness?}

As in the case of 'health', conditions for happiness can be charted inductively using epidemiological research. Many such studies have been performed over the last decade. The results are documented in the earlier mentioned World Database of Happiness (Veenhoven 2010a) and summarized in reviews by Argyle (2002), Diener (1999), Layard (2005) and Veenhoven $(1984,1997)$. What does this research teach us about conditions for happiness?

\section{External Conditions (Top Left Quadrant in Table 1)}

Happiness research has focused very much on social conditions for happiness. These conditions are studied at two levels, at the macro level there are studies about the kind of society where people have the happiest lives and at the micro level there is a lot of research about differences in happiness across social positions in society. As yet there is not much research at the meso level. Little is known about the relation between happiness and labor organization, for example.

Livability of Society In Table 3 we have seen that average happiness differs greatly across nations. Table 4 shows that there is system in these differences. People live happier in rich nations than in poor ones and happiness is also higher in nations characterized by rule of law, freedom, good citizenship, cultural pluriformity and modernity. These data suggest ways for advancing happiness that fit well with current policies.

Figure 2 depicts the relationship between economic development and average happiness in more detail. The scattergram reveals not only a positive correlation, but also a pattern of diminishing utility. This means that investment in economic development is not the best 
Table 4 Happiness and society in 146 nations around 2006

\begin{tabular}{lll}
\hline Characteristics of society & Correlation with happiness & $N$ \\
\hline Affluence & +.69 & 136
\end{tabular}

Rule of law

Civil rights

Corruption

Freedom

Economical

Political

Personal

Inequality

Income inequality

Gender inequality

Citizenship

Participation in voluntary associations

Preference for participative leadership

Pluriformity

$\%$ Migrants

Tolerance of minorities

Modernity

Schooling

Informatization

Urbanization

Explained variance ${ }^{\mathrm{a}}\left(\right.$ adjusted $\mathrm{R}^{2}$ )

Source: World Database of Happiness (Veenhoven 2010a), Data file 'States of Nations 2009' (Variable codes in data file states of nations: Affluence: rgdp_2005, Rule of law: CivilLiberties_2004, Corruption3_2006, Freedom: FreeEconIndex2_2007, PoliticalRifgts_2004, PrivateFreedom_99s; Equality: IncomeInequality1_2005, GenderInstitutionsindex_1990s, Citizenship: VoluntaryActive_1990s2, GoodLeaderParticip_1990s, Pluriformily: Immigrants_2005, Tolerance_1999, Modernity: EducationIndex2_2000.04, PC's_1995, UrbanPopulation_2005. happiness: HappinessLSBW10.11_2000.08)

a The following variables were left out because of the limited number of cases: Participation in Voluntary Associations, Preference for participative leaderschip and Informatization

way for promoting happiness in rich nations. Figure 3 depicts the relation with government effectiveness, which appears to be linear and this means that more happiness can be gained in this way.

Not everything deemed desirable is related to happiness however. Income equality in nations appears to be unrelated to average happiness (Berg and Veenhoven 2010) and there is no relationship either between expenditures for social security and average happiness (Veenhoven 2000b). Likewise, democracy does not seem to add to happiness in all conditions, in particular not in conflict ridden developing nations. 


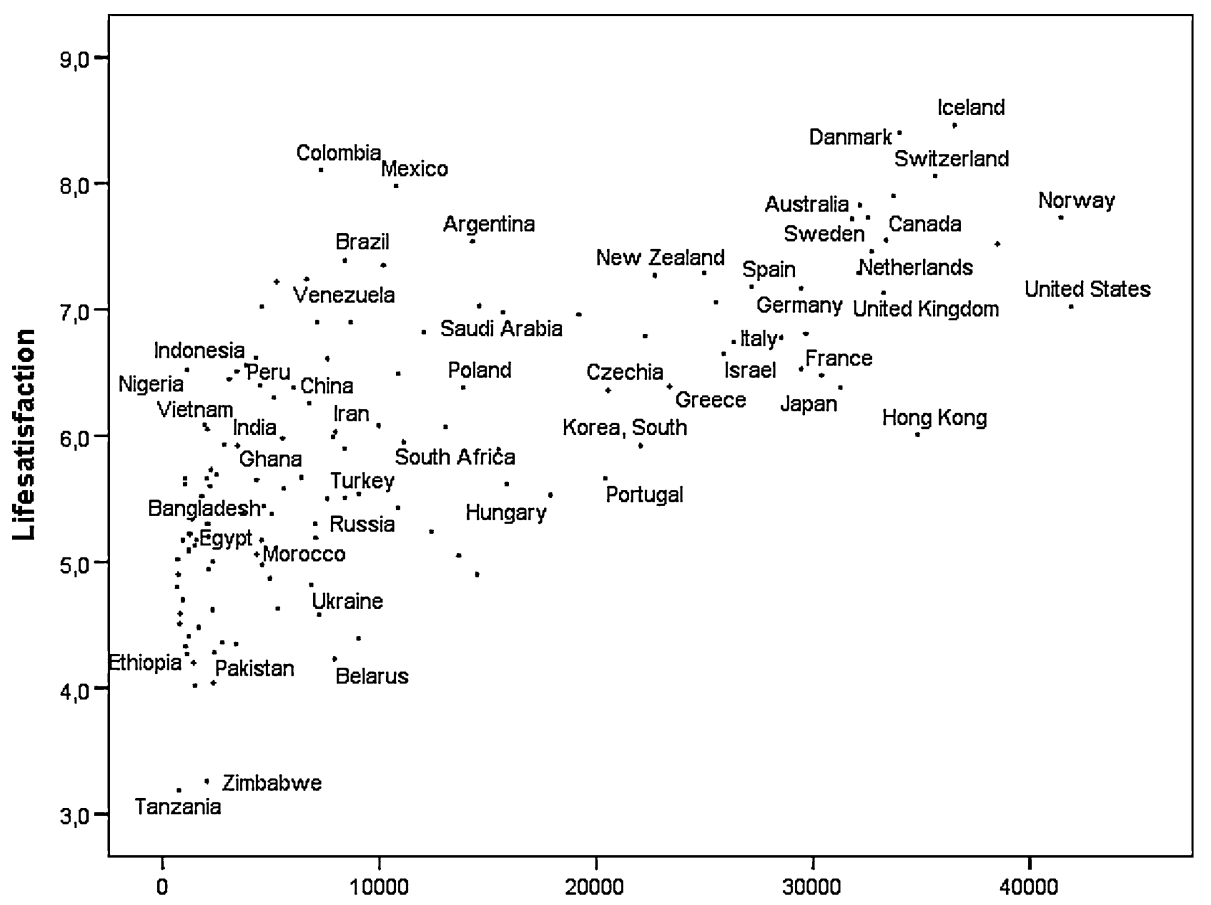

Real Gross Domestic Product 2005

Fig. 2 Average happiness and economic development in nations around 2006

There is much interrelation between the societal characteristics in Table 4; the most affluent nations are also the most free and modern ones. It is therefore difficult to estimate the effect of each of these variables separately. Still it is evident that these variables together explain almost all the differences in happiness across nations; $R^{2}$ is .75!

These findings fit the theory that happiness depends very much on the degree to which living conditions fit universal human needs (livability theory ${ }^{11}$ ). They do not fit the theory that happiness depends on culturally variable wants (comparison theory) or that happiness is geared by cultural specific ideas about life (folklore theory). I have discussed these theoretical implications in more detail elsewhere (Veenhoven and Ehrhardt 1995).

Position in Society Next to the above discussed studies on average happiness across nations, there is much research on differences in individual happiness within nations. A common theme in this kind of studies is the relationship between individual happiness and social position. The main results are summarized in Table 5. Happiness is moderately related to social rank in western nations, while in non-western nations the correlations tend

\footnotetext{
11 This explanation of the difference in average happiness across nations holds that some societies are more 'livable' for human beings than others, that is, that their instutitional arrangements fit better with human nature and allow better gratification of the needs implied in that nature. This explanation implies that there is a universal pattern in the cross-national differences in happiness, which will manifest in a clear pattern of correlation. Cultural explanations rather predict variation in conditions for happiness, which should result in low correlations in Table 4.
} 


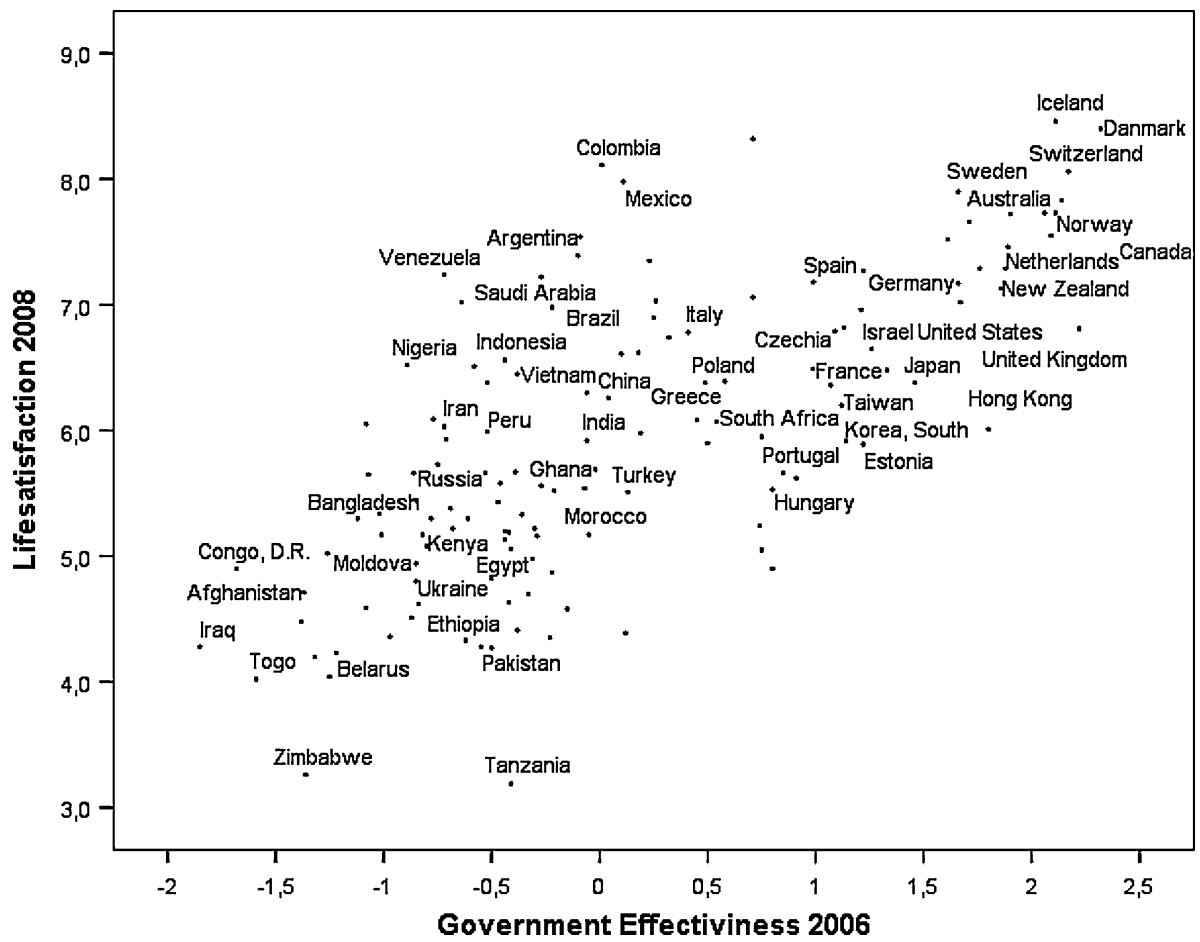

Fig. 3 Average happiness and government effectiveness in nations around 2006

to be stronger. ${ }^{12}$ Happiness is also related to social participation and this relationship seems to be universal. ${ }^{13}$ Being embedded in primary networks appears to be crucial to happiness, in particular being married. This relationship is also universal. ${ }^{14}$ Surprisingly, the presence of offspring is unrelated to happiness, at least in present day western nations. ${ }^{15}$

These illustrative findings suggest that happiness can be improved by facilitating social participation and primary networks, in other words, by creating 'social capital'.

\section{Internal Conditions (Top Right Quadrant in Table 1)}

Happiness depends not only on the livability of the environment, but also on the individual's ability to deal with that environment (see Table 6). What abilities are most crucial?

\footnotetext{
12 World Database of Happiness, Finding report Happiness and Socio-Economic Status: http://www. worlddatabaseofhappiness.eur.nl/hap_cor/top_sub.php?code=S9 (subsection S9.2.1).

13 World Database of Happiness, Finding report Happiness and Social Participation: http://www. worlddatabaseofhappiness.eur.nl/hap_cor/top_sub.php?code=S8 (subsection S8.2).

14 World Database of Happiness, Finding report Happiness and Current Marital Status: http://www.world databaseofhappiness.eur.nl/hap_cor/top_sub.php?code=M2.

15 World Database of Happiness, Finding report Happiness and Having Children: http://www.world databaseofhappiness.eur.nl/hap_cor/top_sub.php?code=C3.
} 
Table 5 Individual happiness and position in society

\begin{tabular}{|c|c|c|}
\hline & Correlation within western nations & Similarity across all nations \\
\hline \multicolumn{3}{|l|}{ Social rank } \\
\hline Income & + & - \\
\hline Education & \pm & - \\
\hline Occupational prestige & + & + \\
\hline \multicolumn{3}{|l|}{ Social participation } \\
\hline Employment & \pm & + \\
\hline Participation in associations & + & + \\
\hline \multicolumn{3}{|l|}{ Primary network } \\
\hline Spouse & ++ & + \\
\hline Children & 0 & $?$ \\
\hline \multirow[t]{7}{*}{ Friends } & + & + \\
\hline & $++=$ strong positive & \\
\hline & $+=$ positive & $+=$ similar \\
\hline & $=$ no relationship & \\
\hline & $-=$ negative & $-=$ different \\
\hline & $?=$ not yet investigated & $?=$ no data \\
\hline & $\pm=$ varying & \\
\hline
\end{tabular}

Source: World Database of Happiness (Veenhoven 2010a), collection of correlational findings

Research findings show that good health is an important requirement ${ }^{16}$ and that mental health is more critical to happiness than physical health. ${ }^{17}$ This pattern of correlations is universal. Intelligence appears to be unrelated to happiness, at least 'school-intelligence' as measured by common IQ tests. ${ }^{18}$

Happiness is strongly linked to psychological autonomy in Western nations. This appears in correlations with inner-control, independence and assertiveness. ${ }^{19}$ As yet we lack data on this matter from Non-Western nations.

Happiness has also been found to be related to moral conviction. The happy are more acceptant of pleasure than the unhappy, and they are more likely to endorse social values such as solidarity, tolerance and love. Conversely, the happy tend to be less materialistic than the unhappy. ${ }^{20}$ It is as yet unclear whether this pattern is universal.

\footnotetext{
16 World Database of Happiness, Finding report Happiness and Physical Health: http://www.world databaseofhappiness.eur.nl/hap_cor/top_sub.php?code=P6.

17 World Database of Happiness, Finding report Happiness and Mental Health: http://www.world databaseofhappiness.eur.nl/hap_cor/top_sub.php?code=M7.

18 World Database of Happiness, Finding report Happiness and Intelligence: http://www.world databaseofhappiness.eur.nl/hap_cor/top_sub.php?code=I3.

19 World Database of Happiness, Finding report Happiness and Current Personality: http://www.world databaseofhappiness.eur.nl/hap_cor/top_sub.php?code=P4 (subsections P4.8 Assertive, P4.54 Independent, P4.58 Inner locus of control).

${ }^{20}$ World Database of Happiness, Finding report Happiness and Value Preference: http://www.world databaseofhappiness.eur.nl/hap_cor/top_sub.php?code=V2 (sections V2.1.1.1 hedonic values, V2.2.2 social values, V2.1.1.3 materialism).
} 


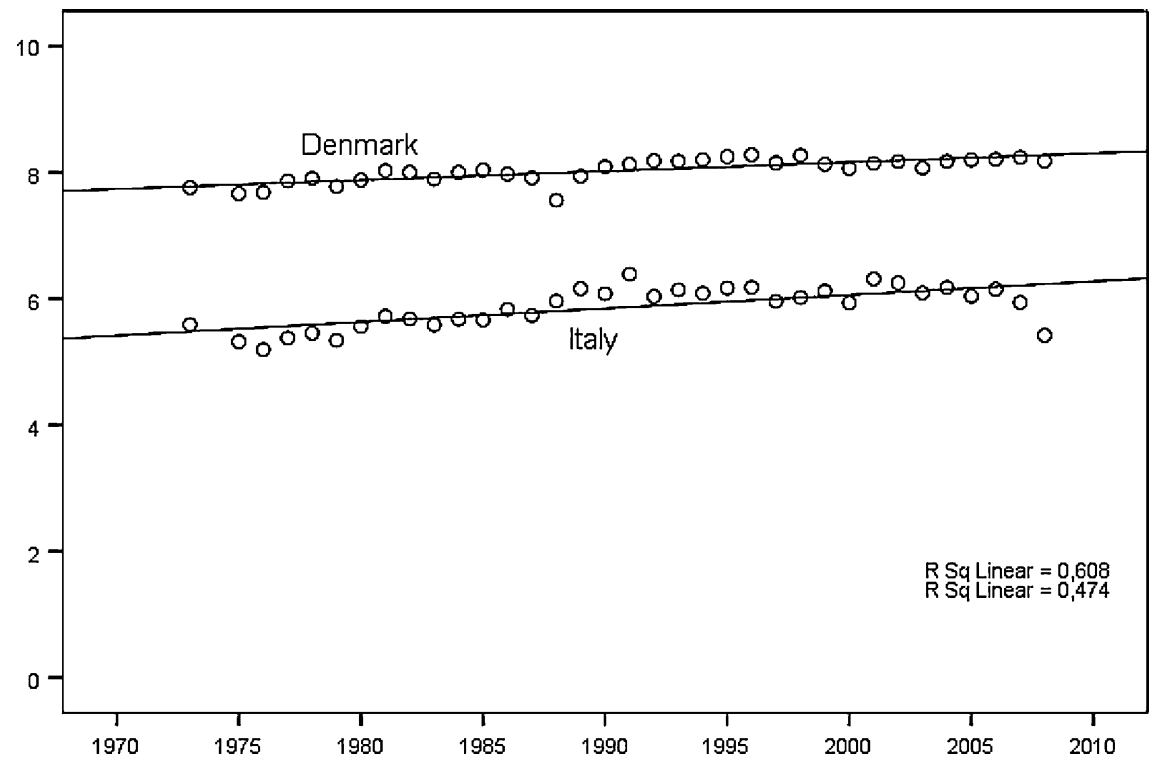

Fig. 4 Trends in average happiness in Denmark and Italy 1973-2008. Source: World Database of Happiness (Veenhoven 2010a), collection of happiness in nations, trend report 2005-1

In sum: Conditions for happiness can be charted empirically; the available data is already very informative.

\subsubsection{Can Happiness be Raised?}

These findings suggest that happiness can be advanced systematically. Public policy can create conditions that appear conductive to happiness, such as freedom, while therapy and education can foster personal characteristics such as independence. Yet these empirical data will not convince the critics who believe in a theory that holds happiness as immutable.

One such theory is that happiness depends on comparison and that standards of comparison adjust to success and failure, although with some delay. In this view, happiness can at best be raised temporarily. Though this theory applies for some kinds of satisfaction, it does not apply for satisfaction with life-as-a-whole. It appears that life-satisfaction is not 'calculated' cognitively, but rather 'inferred' from unreasoned affective experience, which in its turn is related to the gratification of basic needs. The theory that happiness is relative is simply wrong (Veenhoven 1991, 2009).

Another theory holds that we are born either happy or unhappy and that policy interventions can change little as far as this is concerned. A collective variant of this theory is that happiness is a national character trait, for instance that Russian are chronically unhappy because of a cultural tradition of melancholy. This theory is also wrong, followup of individuals show marked changes over the long-term and trend studies of nations show also profound changes, such as in Russia, where happiness dropped dramatically in the late 1990s after the Rubel crisis (Veenhoven 1994, 2001).

Figure 4 presents the trend of happiness over 35 years in Denmark and Italy. The gain is considerable, the Danes gained 0,5 point on the 0 to 10 scale and the Italians 0,7 . The gain 
Table 6 Individual happiness and personal characteristics

\begin{tabular}{lll}
\hline Characteristic & Correlation within western nations & Similarity across all nations \\
\hline Abilities & & ++ \\
Physical health & + & ++ \\
Mental health & ++ & + \\
IQ & 0 & \\
Personality & & + \\
Internal control & ++ & + \\
Extraversion & + & + \\
Aggression & - & \\
Values & & $?$ \\
Hedonism & + & $?$ \\
Materialism & - & + \\
Social & ++ & $+=$ similar \\
\hline & $++=$ strong positive & \\
& $+=$ positive & different \\
& $0=$ no relationship & no data
\end{tabular}

Source: World Database of Happiness (Veenhoven 2010a), collection of correlational findings

in Denmark demonstrates that greater happiness is even possible in the happiest countries of the world. These countries are no exceptions; during this era average happiness has also risen in many other countries (Veenhoven and Hagerty 2006).

From a functional view it is also unlikely that happiness is immutable. As we will see in Sect. 3.2.1, there is good evidence for the theory that happiness serves as a meta-signal in the adaptation process and unresponsive signal systems tend to disappear in the course of evolution.

In sum: Happiness of the great number can be raised, just like public health can be promoted. At best there is an upper limit to happiness, analogous to the ceiling of longevity.

\section{Is Greater Happiness Desirable?}

The fact that public happiness can be raised does not mean that happiness should be raised. Several arguments have been brought against this idea. Happiness has been denounced as trivial and as of less worth than other goal values and it has also been argued that happiness will spoil people. A main objection among philosophers is that the promotion of happiness may require objectionable means. Much of this criticism has been advanced in discussions about different concepts of happiness. The question here is whether these objections apply for happiness as life-satisfaction. 


\subsection{Isn't Happiness Trivial?}

Most people want to be happy and preference for unhappiness is exceptional. Yet the value of happiness has been belittled in several ways, typically on the basis of faulty assumptions about the nature of happiness.

\section{Mere Pleasure?}

In his 'Brave New World' Huxley (1932) paints a tarnished picture of mass happiness. In this imaginary model society, citizens derive their happiness from uninformed unconcern and from sensory indulgence in sex and a drug called 'soma'. This is indeed superficial enjoyment, but is this enjoyment 'happiness'? It is not. This kind of experience was classified as 'pleasure' left-top in Table 2 and distinguished from 'life-satisfaction' right-bottom. Happiness in that latter sense is more than mere pleasure; it last longer and involves an appraisal of one's entire existence.

It is also unlikely that passive consumer slaves, such as depicted in Brave New World, will be satisfied with their life-as-a-whole. Research shows that happiness is typically a fruit of active involvement ${ }^{21}$ and meaningful relations, ${ }^{22}$ while materialism appears to be associated with unhappiness. ${ }^{23}$

\section{Short-Lived Escapism?}

Likewise, Adorno depicted happiness as a temporary escape from reality and rejected it for that reason (Rath 2002). Here satisfaction with one's life as-a-whole is mixed up with short-lived peak-experience, which was classified in the left-bottom quadrant of Table 2.

Do not peak-experiences add to life-satisfaction? Research rather shows a slight negative relationship (Larsen and Diener 1985). Escapism is not conducive to life-satisfaction either, since research shows that happiness is typically a fruit of reality control.

\section{Superficial Success?}

Happiness has also been equated with social success and on that basis rejected as conformist rat-race behavior. This criticism may apply to satisfaction in the domain of career (right-top quadrant in Table 2), but not to satisfaction with life-as-a-whole.

In fact, happy people tend to be independent rather than conformist ${ }^{24}$ and tend not to be materialistic. ${ }^{25}$ Career satisfaction does add to life-satisfaction, but not very much so. ${ }^{26}$ The average correlation is around +.30 , which is less than the correlation with marriage satisfaction. ${ }^{27}$

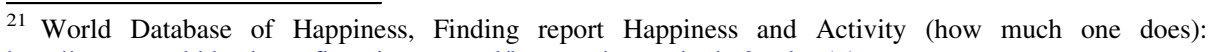
http://www.worlddatabaseofhappiness.eur.nl/hap_cor/top_sub.php?code=A1.

${ }^{22}$ World Database of Happiness, Finding report Happiness and Intimacy: http://www.worlddatabase ofhappiness.eur.nl/hap_cor/top_sub.php?code=I6.

${ }^{23}$ World Database of Happiness, Finding report Happiness and Value Preference: http://www.world databaseofhappiness.eur.nl/hap_cor/top_sub.php?code=V2 (sections, V2.1.1.3 materialism).

${ }^{24}$ World Database of Happiness, Finding report Happiness and Current Personality: http://www.world databaseofhappiness.eur.nl/hap_cor/top_sub.php?code=P4 (subsection P4.54 Independent).

${ }^{25}$ World Database of Happiness, Finding report Happiness and Value Preference: http://www.world databaseofhappiness.eur.nl/hap_cor/top_sub.php?code=V2 (sections, V2.1.1.3 materialism).

${ }^{26}$ World Database of Happiness, Finding report Happiness and Occupation: http://www.world databaseofhappiness.eur.nl/hap_cor/top_sub.php?code=O1 (section O1.4.1.2 satisfaction with occupational career).

${ }^{27}$ World Database of Happiness, Finding report Happiness and Marriage Relationship: http://www.world databaseofhappiness.eur.nl/hap_cor/top_sub.php?code=M3 (section M3.3.3 satisfaction with marriage).
} 


\section{Social Comparison?}

It is commonly assumed that happiness depends on social comparison and that happiness is merely thinking to be better of than the Jones. If so, one can be happy with a miserable life, provided that the Jones are even less well off, or unhappy in heaven because the Jones are on a bigger cloud. The reader may remember that this theory also implies that greater happiness for a greater number is not possible since improvement of the living conditions for all will advance the Jones as much as you, leaving the difference the same.

There is some truth in this theory. We are group-animals, hard-wired to seek social respect and this does often involve us in zero-sum games. Still, social respect is only one of several human needs ${ }^{28}$ and respect is not only gained by being better off. Consequently, the correlation between happiness and social status is not very strong, income, education and occupational prestige explaining less than $5 \%$ of the variance in happiness in modern nations. ${ }^{29}$

\section{Culturally Relative?}

Likewise it is assumed that happiness depends on the meeting of culturally determined standards of success, and that the happiness of present day Americans draws on their ability to live up to the models presented in advertisements. We met with this theory in the above discussion on whether greater happiness can be achieved, one of its implications being that shift in standards nullify the effect of progress (Sect. 2.3).

This theory equates happiness with cognitive contentment and misses the point that happiness depends more on affective experience, which draws on universal human needs (Veenhoven 2009). In this line, research shows much similarity in conditions for happiness in nations all over the world (Veenhoven 2010b). The case of corruption is an example; corruption lowers happiness everywhere, ${ }^{30}$ though there is much cultural variation in the acceptance of corruption. Likewise, marriage is not equally cherished in all cultures, but the married tend to be happier everywhere. ${ }^{31}$

Readers who have been raised with social constructionism may be reluctant to accept this. The following analogy may help them though: There is much cultural variation in likes and dislikes for food, e.g. the eating of pig meat. Still we all need the same nutrients and our health depends on that.

In sum: There are no good reasons to denounce happiness as insignificant.

\subsection{Does Happiness Qualify as a Top Value?}

Agreeing that happiness is desirable is one thing, but the tenet of utilitarianism is that happiness is the highest value. ${ }^{32}$ This claim is criticized on two grounds: firstly it is objected

\footnotetext{
${ }^{28}$ In Maslow's (1954) theory of human needs, social recognition is one of the 'deficiency' needs, next to fysiological needs, safety needs and social needs. Apart from these deficiency needs there is a separate class of 'self actualization' needs.

${ }^{29}$ World Database of Happiness, Finding report Happiness and Summed determinants: http://www.world databaseofhappiness.eur.nl/hap_cor/top_sub.php?code=S15 (subsection S15.2.1 socio-economic factors).

30 World Database of Happiness, Finding report Happiness and Condition of Nation; http://www.world databaseofhappiness.eur.nl/hap_cor/top_sub.php?code=N4 (subsection N4.10.1 Corruption).

31 World Database of Happiness, Finding report Happiness and Current Marital Status: http://www.world databaseofhappiness.eur.nl/hap_cor/top_sub.php?code=M2.

32 In radical utilitarianism happiness is even the only value and all other things have only value to the extent that they are instrumental to happiness. This radical version is central in the philosophical discours.
} 
that it does not make sense to premise one particular value and secondly that there are values that rank higher than happiness. There is a longstanding philosophical discussion on these issues (e.g. Smart and Williams 1973; Sen and Williams 1982), which was recently summarized in a special issue of this journal (Brülde 2007). I will not review these arguments again, but rather consider what the newly gained knowledge about happiness can add to this discussion. In other words, what considerations are missing in the philosophical discours.

\subsubsection{Signal of Wider Thriving}

Above in Sect. 2.1.3 I noted that happiness depends to a great extend on how well we feel affectively; hedonic level of affect being the dominant 'component' of overall happiness.

Why can we feel good or bad? The biological function is evidently to signal that things are good or bad for us. Specific affects are linked to specific needs, e.g. anxiety to the need for safety. Mood functions as a meta-signal and indicates how well we are doing on the whole. Feeling good means that all lights are on green and that we can go ahead, while feeling bad means that there is something wrong and that we should check what that is. This affective signal mechanism seems to exist in all higher animals and its neural basis is found in the evolutionary eldest parts of the human brain (e.g. Grinde 2002; Morris 1992).

What then is 'doing well'? I assume that this is meeting innate 'needs'. Needs are requirements for functioning that are so essential that evolution has safeguarded their gratification by linking these functions to affective signals. This is pretty evident in the case if 'deficiency needs' such as hunger, but seems also to apply to 'growth needs' such as curiosity (Maslow 1954).

Automatic signal systems have their limitations, which are partly compensated by human reason. We can to some extend detect affective signal failure, e.g. when we feel depressed, but know that nothing is wrong. Moreover, we can also evaluate life cognitively, comparing life-as-it-is with standard of how-life-should be (contentment).

Together this means that subjective happiness typically signals objective thriving. There is good evidence for that theory, one piece of evidence is that happy people function better in social relations ${ }^{33}$ and another piece of evidence is that they live longer (Veenhoven 2008b). Elsewhere I have reviewed that evidence in more detail (Veenhoven 1991, 2005, 2009, 2010b).

In this perspective happiness is not only desirable for its own sake, but also for what it denotes. ${ }^{34}$ Policies that aim at greater happiness of a greater number produce not only more hedonic experience, but also foster wider human thriving.

In this context it is easy to see the limitations of Nozick's classic argument. Nozick (1989: 99-117) claims that few people would enter a machine that makes them feel perfectly happy and concludes on that basis that happiness disqualifies as the highest value. This argument applies to the signal as such, but forgets what it means. The message of happiness is that we are functioning well and for that reason there is little enthusiasm for feeling happy while not functioning at all.

\footnotetext{
33 World Database of Happiness, Finding report Happiness and Intimacy: http://www.worlddatabase ofhappiness.eur.nl/hap_cor/top_sub.php?code=I6 (See also links to related subjects mentioned in this report).

34 This begs the question whether we not better assess 'triving' as such and in particular 'need gratification'. The answer is that we cannot measure these things, We can only infer them by their manifestations, such as happiness and longevity, which are also desirable in their own right.
} 


\subsubsection{Signal of Optimal Combinations}

Another novelty is in the insight that 'quality' of external living conditions depends on inner life-abilities and vice versa. Remember Table 1. Democracy is generally deemed to be good, but it does not work well with anxious and uneducated voters. Likewise, conformism is generally deemed to be bad but can be quite functional in collectivist conditions.

This helps us to understand that general end-values cannot be found in the top quadrants of Table 1. Instead, end values are to be found in the bottom of Table 1, and in particular in the bottom-right quadrant. Happiness and longevity indicate how well a person's lifeabilities 'fit' the conditions in which that person lives and as such reflects more value than is found in each of the top quadrants separately. Happiness is a more inclusive merit than most other values, since it reflects an optimal combination.

A related point is that there are limits to most values, too much freedom leads into anarchy, too much equality into apathy. The problem is that we do not know where the optimum level lies and how optima vary in different value combinations. Here again happiness is a useful indicator. If most people live long and happily the mix is apparently livable. I have elaborated these points in more detail elsewhere (Veenhoven 1996, 2000a).

\subsubsection{Happiness Ranks High in Public Opinion}

Another strand of empirical research is survey studies on value preferences. Happiness ranks high in such studies, typically together with 'health' that is also a manifestation of human thriving (e.g. Harding 1985). There is a remarkable contrast between the valuation of happiness by the general public and the reservations about happiness among professional moralists, which is an interesting object of study in its own. Whatever the reason, this is a new fact that must be taken into account.

In sum: If one opts for one particular end-value, happiness is a good candidate. If not, happiness qualifies at least as a core value.

\subsection{Will promotion of happiness go at the cost of other values?}

Even if there is nothing wrong with happiness in itself, maximization of it could still work out negatively for other valued matters. Critics of utilitarianism claim this will happen. They foresee that greater happiness will make people less caring and responsible and fear that the premise for happiness will legitimize a-moral means such as torture of dissidents. This state of affairs is also described in 'Brave New World', where citizens are concerned only with petty pleasures and the government is dictatorial.

\subsubsection{Does Happiness Spoil?}

Over the ages, preachers of penitence have glorified suffering. This sermonizing lives on in the idea that happiness does not bring out the best of us. Happiness is said to nurture selfsufficient attitudes and to make people less sensitive to the suffering of their fellows. Happiness is also seen to lead to complacency and thereby to demean initiative and creativeness. It is also said that happiness fosters superficial hedonism and that these negative effects on individuals will harm society in the long run. Hence promotion of happiness is seen to lead to societal decay; Nero playing happily in a decadent Rome that is burning around him. 
One of the reasons for this negative view is than happiness is equated with contentment and in that line it is assumed that we will be passive if we have all we want. Above in Sect. 2.1.3 I have argued that cognitive contentment is only one of the 'components' of happiness and not the most important one. Another reason is that the critics of happiness (mostly philosophers) tend to have a blind eye for the functions of positive affect. ${ }^{35}$ As noted above in Sect. 3.2.1, happiness signals adaptational success, and as such it also works as a go-signal. If an organism feels good, it knows that the coast is clear and that it can go ahead, whereas negative affect rather inhibits action.

This view is supported in an emerging strand of empirical research on effects of happiness (e.g. Veenhoven 1988; Lyubomirsly et al. 2005). The observed effects are typically positive: happiness fosters activity and facilitates involvement in tasks and in contact with other people. For instance: happy people tend to be better citizens, they work more ${ }^{36}$ and engage more in civic organizations. ${ }^{37}$ There is also good evidence that happiness lenghtens life (Veenhoven 2008b). Much of these effects are summarized in Fredrickson's (2000) 'Broaden and Built theory', which holds that positive effects broadens our behavioral scope and that this results in a built-up of resources.

All this does not deny that happiness may involve some negative effects. There are for instance indications that happy people take more risk. Still the positive effects are clearly dominant.

\subsubsection{Does Greater Happiness Require A-Moral Means?}

The main objection against utilitarianism is that the greatest happiness principle justifies any way to improve happiness and hence permits morally rejectable ways, such as genetical manipulation, mind-control and political repression. In that line it is also argued that the rights of minorities can be sacrificed on the altar of the greatest number, e.g. that slavery is justified when that adds to the happiness of the majority.

The possibility of such undesirable consequences is indeed implied in the logic of radical utilitarianism, but is it likely to materialize? The available data suggest this is not the case. In Table 4 we have seen that citizens are happiest in nations that respect human rights and allow freedom. It also appeared that people are happiest in the most educated and informatized nations. Likewise Table 6 showed that happy people tend to be active and independent. In fact, there is no empirical evidence for any real value conflict.

This holds also for the objection that happiness of the greatest number can go together with unfair differences in happiness. Research shows a strong negative correlation between average level of happiness and inequality of happiness in nations. ${ }^{38}$ This is is partly a matter of logic; if the average on scale $0-10$ is ten, the standard deviation is zero. The correspondence is also due to common sources of both level and equality of happiness (Ott 2005).

\footnotetext{
35 An illustration of this blind eye in the philosophy of happiness is that the signal function of affect is not mentioned in any of the articles in Brülde (2007).

36 World Database of Happiness, Finding report Happiness and Employment: http://www.world databaseofhappiness.eur.nl/hap_cor/top_sub.php?code=E2.

37 World Database of Happiness, Finding report Happiness and Participation in Voluntary associations: http://www.worlddatabaseofhappiness.eur.nl/hap_cor/top_sub.php?code=S7.

38 World Database of Happiness, Finding report Happiness and Condition of Nation; http://www.world databaseofhappiness.eur.n1/hap_cor/top_sub.php?code=N4 (subsection N4.8.5.1 Inequality of happiness).
} 
In sum: In theory the pursuit of greater of happiness for a greater number can involve means that are morally rejectable, but in practice this appears not to be the case. So, common philosophical qualms about the principle are not very realistic. ${ }^{39}$

\section{Conclusion}

These empirical tests falsify all the theoretical objections against the greatest happiness principle. The criterion appears practically feasible and morally sound. Hence the greatest happiness principle deserves a more prominent place in policy making.

Acknowledgments I thank the editor of this special issue and two anonimous reviewers for their thoughtful comments. I also thank my co-workers in the World Database of Happiness, without the effort of which I would have missed much of the available research data on happiness.

Open Access This article is distributed under the terms of the Creative Commons Attribution Noncommercial License which permits any noncommercial use, distribution, and reproduction in any medium, provided the original author(s) and source are credited.

\section{References}

Argyle, M. (2002). The psychology of happiness. London: Methuen. (3rd revised edition).

Bentham, J. (1789). Introduction to the principles of morals and legislation. London: Oxford University Press (Reprint 1996).

Berg, M., \& Veenhoven, R. (2010). Income inequality and happiness in nations, Forthcoming in Bent Greve (Ed.) Social policy and Happiness in Europe, Edward Elgar.

Brickman, P., \& Campbell, D. T. (1971). Hedonic relativism and planning the good society. In M. H. Appley (Ed.), Adaptation level theory: A symposion' (pp. 287-302). London: Academic Press.

Brülde, B. (Ed.). (2007). Happiness and the good life. Special issue of the Journal of Happiness Studies, 8/1.

Buijs, P. M. (2007). De Eeuw van het Geluk: Nederlandse Opvattingen over Geluk ten tijde van de Verlichting 1658-1835.(The Age of Happiness: Dutch Opinions of Happiness during the Enlightenment), PhD dissertation University of Utrecht.

Diener, E. \& Oishi, S. (2004). Are Scandinavians happier than Asians? Issues in comparing nations on subjective wellbeing. In F. Columbus (Ed.), Asian Economic and political Issues, 10, 1-25.

Diener, E., Suh, E., \& Oishi, S. (1997). Recent findings on subjective well-being. Indian Journal of Clinical Psychology, 24, 25-41.

Diener, E., et al. (1999). Subjective well-being: Three decades of progress. Psychological Bulletin, 125, 276-301.

Ehrhardt, J. J., Saris, W. E., \& Veenhoven, R. (2000). Stability of life-satisfacton over time, analysis of ranks in a national population. Journal of Happiness Studies, 1, 177-205.

Ekman, P., \& Friesen, P. W. (1975). Unmasking the face. Englewood Cliffs: Prentice Hall.

Fredrikson, B. L. (2000). Cultivating positive emotions to optimize health and wellbeing, Prevention and Treatment, 3, article 1a.

Freud, S. (1948) (1929). Das Unbehagen mit der Kultur, Gesammte Werke aus den Jahren 1925-1931. Frankfurt-am Main: Fisher Verlag.

Gerson, E. M. (1976). On quality of life. American Sociological Review, 41, 793-806.

Grinde, B. (2002). Happiness in the perspective of evolutionary psychology. Journal of Happiness Studies, 3, 331-354.

Harding, S. D. (1985). Values and the nature of psychological well-being. In M. Abrams, D. Gerard \& N. Timms (Eds.), Values and social change in Britain (pp. 227-252). London: McMillan.

Huxley, A. (1932). Brave new world. Stockholm: Continental Book.

Huxley, A. (1935). Brave new world. New York: HaperCollins (Reprint 1998).

39 This is not to say that the promotion of happiness matches all other values in all conditions. Future research should focus on trade-offs and chart possible contingencies. 
Larsen, R. J., \& Diener, E. (1985). A multitrait-multimethod examination of affect structure: Hedonic level and emotional intensity. Journal of Personality and Individual Differences, 6, 631-636.

Lane, R. E. (2000). The loss of happiness in market democracies. New Haven: Yale University Press.

Layard, R. (2005). Happiness: Lessons from a new science. New York, USA: Penguin.

Lyubomirsly, S., Diener, E., \& King, E. (2005). The benefits of frequent positive affect: Does happiness lead to success? Psychological Bulletin, 131, 803-855.

Maslow, A. H. (1954). Motivation and personality. NY, USA: Harper \& Row.

Mauzi, R. (1960). L'Idée du Bonheur dans la Litérature et la Pensée Française au 18e Siècle. (The Idea of Happiness in French Thought in the 18th Century). Paris, France: Librairie Armand Colin.

McDowell, I., \& Newell, C. (1987). Measuring health: A guide to rating scales and questionnaires. New York: Oxford University Press.

Morris, W. N. (1992). A functional analysis of mood in affective systems. In M. S. Clark (Ed.), Emotion (pp. 256-293). London, UK: Sage.

Nozick, R. (1989). The examined life. New York, USA: Simon \& Schuster.

Ott, J. C. (2005). Level and equality of happiness in nations: Does greater happiness of a greater number imply greater inequality in happiness? Journal of Happiness Studies, 6, 397-420.

Parfit, D. (1984). Reasons and persons. New York: Oxford university Press.

Rath, N. (2002). The concept of happiness in Adorno's critical theory. Journal of Happiness Studies, 3, 1-21.

Schimmack, U., \& Diener, E. (Eds.). (2003). Experience sampling methodology in happiness research. Special issue of the Journal of Happiness Studies, 4-1.

Sen, A. (1992). Capability and wellbeing. In M. Nussbaum \& A. Sen (Eds.), The quality of life. Oxford: Clarendon.

Sen, A., \& Williams, B. (Eds.). (1982). Utilitarianism and beyond. London: Cambridge University Press.

Smart, J. J., \& Williams, B. (1973). Utilitarianism, for and against. London: Cambridge University Press.

Sumner, L. W. (1996). Welfare, happiness and ethics. New York: Oxford University Press.

VanPraag, B. M. (1993). The relativity of welfare. In M. Nussbaum \& A. Sen (Eds.), The quality of life (pp. 362-385). Oxford: Clarendon Press.

VanPraag, B. M., \& Ferrer-i-Carbonell, A. (2004). Happiness quantified: A satisfaction calculus approach. NY, USA: Oxford University Press.

Veenhoven, R. (1984). Conditions of happiness. Dordrecht: Kluwer Academic.

Veenhoven, R. (1988). The utility of happiness. Social Indicators Research, 20, 333-354.

Veenhoven, R. (1991). Is happiness relative? Social Indicators Research, 24, 1-34.

Veenhoven, R. (1993). Happiness in nations: Subjective appreciation of life in 56 nations 1946-1992. Rotterdam: RISBO -Erasmus University Rotterdam.

Veenhoven, R. (1994). Is happiness a trait?: Test of the theory that a better society does not make people any happier. Social Indicators Research, 32, 101-160.

Veenhoven, R. (1996). Happy life-expectancy: A comprehensive measure of quality-of-life in nations. Social Indicators Research, 39, 1-58.

Veenhoven, R. (1997). Progrès dans la compréhension du bonheur. Revue Québécoise de Psychologie, 18-2, 29-74.

Veenhoven, R. (1998). Vergelijken van geluk in landen (comparing happiness across nations). Sociale Wetenschappen, 42-4, 58-84.

Veenhoven, R. (2000a). The four qualities of life: Ordering concepts and measures of the good life. Journal of Happiness Studies, 1, 1-39.

Veenhoven, R. (2000b). Wellbeing in the welfare state, level not higher, distrubution not more equitable. Journal of Comparative Policy Analysis, 2, 91-125.

Veenhoven, R. (2001). Are the Russians as unhappy as they say they are? Comparability of self reports across nations. Journal of Happiness Studies, 2, 111-136.

Veenhoven, R. (2005). Happiness in hardship. In L. Bruni \& P. L. Porta (Eds.), Economics and happiness: Framing the analysis (pp. 243-266). Oxford: Oxford University Press.

Veenhoven, R. (2008a). Comparability of happiness across nations, School of Sociology and Social Work Journal no. 104. Kobe, Japan: Kwansei Gakuin University.

Veenhoven, R. (2008b). Healthy happiness: Effects of happiness on physical health and the consequences for preventive health care. Journal of Happiness Studies, 9, 449-464.

Veenhoven, R. (2009). How do we assess how happy we are? In A. Dutt, A. Dutt, \& B. Radcliff (Eds.), Happiness, economics and politics (pp. 45-69). USA: Edward Elger Publishers. Chapter 3.

Veenhoven, R. (2010a). World database of happiness, ongoing register of scientific research on subjective enjoyment of life. http://worlddatabaseofhappiness.eur.nl. 
Veenhoven, R. (2010b). How universal is happiness? In E. Diener, J. Helliwel, \& D. Kahneman (Eds.), International differences in wellbeing. Oxford: Oxford University Press (Chapter 11 in press).

Veenhoven, R., \& Ehrhardt, J. (1995). The cross-national pattern of happiness: Test of predictions implied in three theories of happines. Social Indicators Research, 43, 33-86.

Veenhoven, R., \& Hagerty, M. (2006). Rising happiness in nations, 1946-2004. A reply to easterlin. Social Indicators Research, 77, 1-16.

Wessman, A. E., \& Ricks, D. F. (1966). Mood and personality. New York: Holt, Rhinehart \& Winston. 